\title{
UMA TEORIA DA JUSTIÇA INTERNACIONAL: A SUPERAÇÃO DA “GUERRA DE TODOS CONTRA TODOS" RUMO À EQUIDADE PERPÉTUA ${ }^{1}$
}

\author{
A THEORY OF INTERNATIONAL JUSTICE:THE OVERCOMING OF THE \\ "WAR OF ALL AGAINST ALL” TO THE PERPETUAL \\ FAIRNESS
}

\author{
FERNANDO CÉSAR COSTA XAVIER ${ }^{2}$ \\ (UFRR / Brasil)
}

\begin{abstract}
Resumo
O projeto de uma Justiça Internacional, em seus variados modelos, aponta para a substituição, no cenário teórico das relações internacionais, do outrora influente realismo político pela promissora reformulação do projeto normativo do Kant de À Paz Perpétua. Embora o realismo tenha obtido certo êxito na leitura da configuração contemporânea da ordem internacional, sobretudo do pós-guerra, essa corrente teórica não logrou sustentar justificações racionalmente aceitáveis acerca de como se deveria contrapor, e enfim superar, o conjunto de contingências que tornam insegura e injusta a ordem global contemporânea. Diante disso, determinados autores julgam conveniente insistir na retomada do paradigma kantiano. Nessa esteira, o jusfilósofo Peter Koller propõe o arrefecimento da soberania estatal, bem como da razão de Estado, em favor de uma teoria de justiça distributiva aplicável ao plano internacional. O presente texto acompanha a essência do pensamento de Koller, mas acrescenta que é indispensável que uma teoria da justiça internacional assuma irrestritamente os postulados da tradição deontológica kantiana. E, com a mesma convicção, ressalta o papel dialógico e emancipatório que a chamada "sociedade civil global" pode desempenhar na ordem internacional do séc. XXI.

Palavras-chave:Justiça internacional; realismo político; soberania; deontologia kantiana; sociedade civil global
\end{abstract}

\begin{abstract}
The project of an International Justice, in its variable modes, goes towards a substitution, in the theoretical field of international affairs, of once influential politic realism by the promising reformulation of the normative project of Perpetual Peace of Kant. Although the realism had obtained some success via the lecture of the contemporary configuration of international law, especially postwar, this theoretical tradition could not support plausible rational justifications of how we should oppose, and finally overcome, all the contingencies that make the contemporary global order unsafe and unfair. Thus, some authors believe they should insist on the resumption of the Kantian paradigm. In this connection, Peter Koller, philosopher of law, proposes the weakening of the ratio of state, towards a theory of distributive justice applicable to the international level. This text accompanies the essence of Koller's thoughts, but adds that it is essential that a theory of international justice takes unrestrictedly the postulates of the tradition of Kantian ethics, and, with the same conviction, shows the dialogue and emancipatory role that the socalled "global civil society" can play in international law in the 21 st century.
\end{abstract}

Key-words:International justice; politic realism; sovereign; Kantian ethics; global civil society

\section{Introdução}

A ideia de elaboração de um modelo de justiça aplicável à relação entre os povos não repre- 
senta nenhuma novidade. Sobretudo a partir de $\grave{A}$ Paz Perpétua (1795), de Kant ${ }^{3}$, ou antes com o Abade St. Pierre (1756), projetos teóricos dedicados à justiça e à paz passaram a ser propostos para o plano internacional. A crença na benesse inerente aos pactos internacionais, que puseram fim às guerras régias e confessionais na Europa do séc. XVI (Paz de Vestfália), tornou-se necessariamente difundida no início da era moderna, de modo que a tradição deontológica inaugurada por Kant passou a acompanhar os processos de composição nas relações internacionais pré-contemporâneas.

Não obstante, alcançado o séc. XX, o pensamento político-filosófico que se seguiu foi abandonando gradualmente a fundamentação na normatividade deontológica, sobretudo como reflexo político dos conflitos bélicos que assumiram projeção mundial e produziram traumas sem precedentes, passando a ligar-se invariavelmente a uma visão de mundo realista - ou, para alguns, pessimista $^{4}$ - para a qual a proposta kantiana de uma paz duradoura não passaria de uma ingenuidade do passado.

\section{O realismo político e a retomada da tradição deontológica}

Na segunda metade do séc. XX, em face da configuração geopolítica do pós-Guerra, algumas abordagens do chamado "realismo político" (Morgenthau, Wight, Wendzel, Mearshaimer), promissoras graças às contingências históricas que marcavam o período em que foram formuladas, encarregaram-se de instituir modelos de leitura das relações internacionais centrados em uma visão contratualista semelhante ao modus vivendi hobbesiano ${ }^{5}$. Nesses modelos, as justificativas para a busca por "consenso" em torno da paz mundial ancoravam-se em argumentos característicos da razão estratégica ${ }^{6}$. O cenário global passava então a ser visto como um tipo de "arena", na qual as tensões entre forças político-econômicas opostas deveriam ser freadas e contrabalançadas através de acordos impostos por Estados-potências e mercados globais, portanto aceitos (aceitação prática), mas muitas vezes não aceitáveis (aceitabilidade racional).

Em face de novos cenários geopolíticos criados a partir do dúplice processo de globalização/ regionalização ocorrido na segunda metade do séc. XX, em que se passou a contestar a postura individualista dos Estados nacionais soberanos ${ }^{7}$, o cenário teórico voltou a ceder espaço às teorias normativas deontológicas ${ }^{8}$. Isso veio coincidir com os 200 anos da publicação de $\dot{A}$ paz perpétua, rememorados e comemorados pela filosofia recente ${ }^{9}$. Surgia novamente a necessidade de se justificar as bases para a confiança, o respeito mútuo, a segurança e o diálogo simétrico, sem os quais os projetos de instituição de organizações internacionais não poderiam transigir para o formato de comunidades político-jurídicas comprometidas, dentre outras coisas, com os direitos humanos e a paz mundial.

Abordagens específicas como as de Peter Koller, Ulrich K. Preuß, Otfried Höffe, Wolfgang 
Kersting e outros que, resgatando a perspectiva kantiana ${ }^{10}$ e associando-se de algum modo ao kantismo reformulado dos procedimentalistas ${ }^{11}$, pretendem hoje desvelar os pressupostos para um efetivo consenso democrático em um sistema de relações equitativas que se estabeleça entre todos os membros da ordem internacional.

No entanto, para o jusfilósofo austríaco Peter Koller ${ }^{12}$, notadamente, a consolidação de uma ordem global justa esbarra na visão clássica de soberania nacional. Para ele, a limitação (ou relativização) da soberania dos Estados nacionais é condição de possibilidade para a implementação de princípios de justiça no plano internacional hodierno. A tese central de Koller, acerca da relação diametralmente oposta entre soberania nacional e justiça internacional, está longe de ser inovadora, mas, com o presente artigo, pretende-se mostrar que uma abordagem normativa da questão da justiça no plano internacional, como a que é, em todo caso, esboçada por esse autor, é imprescindível para se legitimar os processos hoje em curso de "macrorregionalização" político-jurídica das instâncias supranacionais (comunitárias) ${ }^{13}$.

Nesse sentido, quero dizer que o normativismo deontológico, em forma de uma proposta dialógica, nos moldes da ética da discussão, é a única alternativa viável a um padrão de justiça internacional; e deve substituir o realismo, tal como Rawls pretendeu que a sua teoria da justiça substituísse as doutrinas então vigentes no contexto anglo-saxão no início da década de 1970 .

\section{A justiça como ideal factível para o âmbito da sociedade internacional dos povos, e não apenas para o plano nacional das sociedades civis}

Um primeiro problema a ser enfrentado, nesta empreitada, é que, segundo é oponível aos procedimentalistas, a ideia de justiça internacional seria demasiado "idealizante", no sentido de que laboraria com categorias do entendimento que não seriam observáveis no mundo dos fatos.

Alguns autores, que se enquadrariam na corrente realista, lembram que mesmo a visão kantiana da ordem internacional havia constatado que os países viveriam - ao menos nos sécs. XVII e XVIII -, em um estado de natureza ${ }^{14}$, sem regras claramente definidas, em um panorama que lembrava o contrato lupino descrito por Hobbes em relação à sociedade dos indivíduos. Como se poderia então imaginar o respeito esclarecido aos direitos humanos, que implicasse a limitação das soberanias nacionais, em uma "alcateia de países"?

Em relação a isso, Rawls, n'O direito dos povos (1999) $)^{15}$, defende a ideia de uma “utopia realista", com o que quer significar a projeção da sua concepção de justiça como equidade para as relações internacionais. Essa ideia "utópico-realista" de Rawls segue a noção de fredus pacificum (federação pacífica) que Kant sustenta em À paz perpétua, no sentido de que a liberdade e a paz não podem ser asseguradas plenamente no plano interno enquanto não houver um acordo externo geral 
que garanta a não-agressão e a não-interferência na ordem interna dos Estados, devendo estes gozar de autodeterminação plena. Conforme explica Sérgio Sérvulo da Cunha, "a proposta [de Rawls] está conforme a ideia de Kant de que um regime constitucional precisa estabelecer um Direito dos Povos efetivo, para realizar plenamente a liberdade dos seus cidadãos"16.

A crença de Rawls, nesse escrito derradeiro, culmina na esperança de que, dada a natureza do mundo social, as sociedades democráticas constitucionais razoavelmente justas poderiam, no futuro, coexistir como membros em uma Sociedade dos Povos, sem que isso implicasse a afirmação de uma noção contra-intuitiva.

É verdade que se discute se é possível que se efetive a proposta de universalização das democracias constitucionais tomadas como modelos por Rawls, uma vez que são acusadas de conter uma substância liberal incompatível com o pluralismo de cosmovisões, e que também se alega que as noções de sociedade de povos e de contrato - em detrimento, respectivamente, de comunidade internacional e de procedimento deliberacionista - seriam inapropriadas para se fundamentar um projeto normativo de justiça internacional. Entretanto, a essência da ideia de uma "utopia realista" é que a tese realista de que há um "egoísmo" inato aos Estados nacionais modernos pode ser refutada. Com isso parece concordar Koller: "O caráter fantasioso dessa opinião pode gerar discordância racional significativa [...] mas não quer dizer que não funcione" ${ }^{17}$.

Uma vez que a desconfiança que determina a conduta dos Estados soberanos não é um fato da natureza, o consenso entre os países mostra-se possível - e eu acrescentaria que, se a desconfiança passa a ser substituída pela confiança, referido consenso torna-se, além de possível, desejável.

\section{As pessoas, não os Estados, como os sujeitos internacionais principais}

Outro problema que aparece, ligado à tese da natureza traiçoeira dos Estados, é que o desenvolvimento material das ordens internas depende em muitos casos de uma postura estratégica dos Estados na ordem internacional. Aqui, supõe-se que há uma linha divisória, e uma correspondente tensão, entre as ordens nacional e internacional, sendo que, na segunda, não se poderia conceber um mundo da vida ${ }^{18}$ (tal como entende Habermas). Os Estados, ou mais propriamente os governos dos Estados, estariam intrinsecamente ligados a uma racionalidade estratégica (orientada pela lógica do poder), sendo-lhes estranho o agir comunicativo baseado na lógica do entendimento. Esse problema, no entanto, é afastado à medida que se percebe que o sujeito da ordem internacional é o mesmo da ordem nacional, isto é, a pessoa individualmente concebida.

Koller tem razão ao defender que o paradigma moral, em relações internacionais, deve se assentar não mais nos Estados nacionais, senão nos próprios seres humanos, entendidos como pessoas autônomas que figuram como sujeitos de um direito cosmopolita (no sentido kantiano); ou 
seja, é afirmar-se a autonomia moral das pessoas em detrimento da autonomia moral dos Estados.

Nesse passo, Koller refuta a pressuposição de que "o mundo consiste de um certo número de diferentes sociedades que, em geral, subsistem independentemente uma da outra" ${ }^{19}$, referindo, nessa passagem, que mesmo a teoria contemporânea de Rawls estaria equivocadamente assentada em tal pressuposição. Daí se interpretar que Koller, embora concorde com o ideal de justiça universal contida em $O$ direito dos povos, acredita que esse ideal deve enveredar por um itinerário diferente da simples superposição, mutatis mutandis, da justiça como equidade de Rawls para a esfera internacional. Koller, que parece ter uma visão mais compreensiva do mundo atual, entende que a amalgamação das sociedades na ordem global teria como insatisfatória uma "concepção de justiça política, não metafísica"20.

Isto compreendido, pode-se visualizar um projeto de "contracolonização", por parte de um mundo da vida representado por uma "sociedade civil global" 21 , que objete a razão estratégica característica da lógica baseada em relações de poder e lucratividade - estas inerentes, respectivamente, aos sistemas de governo e de mercado.

\section{Uma teoria da justiça internacional}

Uma teoria da justiça aplicada ao plano internacional deveria consistir em um modelo de justiça distributiva ${ }^{22}$ capaz de assegurar a autonomia das pessoas em nível nacional ou internacional, ou antes, de diminuir a noção geográfica de fronteira como obstáculo à interação entre as pessoas, de modo a garantir a dignidade destas onde quer que se encontrem no mundo, para que possam dispor de um nível igualitário de sociabilidade e comunicação nas diversas relações que possam travar entre si. Como diz Koller, “[...] uma ordem internacional seria moralmente legítima, se e somente se, em vista das condições que persistem no mundo, ela puder ser aceita razoavelmente, a partir de uma perspectiva imparcial, por cada um ou cada uma, sem considerar a sua vinculação a qualquer país" ${ }^{23}$. Todavia, essa teoria da justiça, calcada em princípios determinados, lida com um problema adicional, relativo ao estágio atual das relações internacionais.

Desde Kant, passando por Rawls, a ideia de um Estado Mundial regulador foi frequentemente rejeitada, alegando-se que tal entidade careceria de legitimidade e tenderia inevitavelmente ao despotismo. Rawls o afirma no $\S 4.1$ d'O direito dos povos: "Sigo o exemplo de Kant [...] ao pensar que um governo mundial - com o que me refiro a um regime político unificado, com poderes jurídicos normalmente exercidos por governos centrais - seria um despotismo global", diz ele, complementando imediatamente "ou, então, governaria um império frágil, dilacerado pela guerra civil frequente, quando várias regiões e povos tentassem conquistar liberdade e autonomia políticas".

No entanto, quem regularia a obediência aos princípios da justiça internacional voltada à 
proteção global das pessoas? Parece, à primeira vista, que não se teria "a garantia de que as partes envolvidas, em especial os Estados, aceitariam realmente princípios razoáveis de uma ordem internacional ideal, já que não existe uma autoridade supranacional, capaz de efetivamente impô-los", conforme afirma Koller ${ }^{24}$. Em seguida, conclui o autor que: "Essa situação - chamemo-la de situação de imperfeição moral - levanta a questão, se e em que medida, fundamentalmente, pode-se exigir uma conduta moral nas relações internacionais" 25 .

Embora os Estados sejam substituídos como os atores principais pelas pessoas, no domínio da moral, ainda assim eles continuam a ser levados em consideração, e, em sua posição secundária, eles [Estados] teriam o importante papel de assegurar a observância aos princípios de justiça internacional racionalmente aceitáveis às pessoas. Mas como se poderia "exigir uma conduta moral nas relações internacionais"?, ou, dito de outro modo: de que forma se lidaria com essa 'situação de imperfeição moral' apontada por Koller ${ }^{26}$ ?

Dentre as respostas possíveis, Koller refere que demandas morais não seriam obrigatórias se parecessem justificáveis apenas em condições favoráveis, sendo acatadas pela maioria, mas não por todos e qualquer um, de vez que isso resultaria "num derrotismo moral que encontramos na concepção de Hobbes" ${ }^{27}$, e que é exatamente o que o presente artigo pretende ver sepultado.

\section{Por uma teoria deontológica pura}

Seguindo outras alternativas, ainda assim a teoria de Koller vem me parecer insatisfatória, à medida que superestima o que ele denomina "condições moralmente deficientes da realidade" 28 . Parece-me assim, não apenas porque o respeito por iniciativas relativamente recentes consubstanciadas em tratados internacionais de forte apelo moral (p. ex., a instituição do Tribunal Penal Internacional) é cada vez mais visível e põe em xeque isso que me parece "pessimismo" da parte de Koller, mas também, e sobretudo, porque, a partir da referida pressuposição de imperfeição moral, dá-se ensejo a uma abordagem que vejo como epistemologicamente inadequada.

Koller expressamente propõe, a fim de lidar com as contingências, mas sem querer perder o viés deontológico, uma teoria bifurcada: uma voltada para um mundo ideal, outra para um mundo não-ideal, esta última "adequada" para situações empíricas em que a moralidade não pode ser rigorosamente garantida ${ }^{29}$. Ele chega a dizer que pretende defender uma posição intermediária entre um modelo kantiano e outro que entendo como consequencialista, vez que ocupado do controle de contingências reais.

A meu ver, o fim definitivo da soberania do Estado é motivo de preocupação para Koller para ele, bastaria que a soberania fosse limitada -, pois sem o Estado dotado de alguma soberania não se poderia garantir nem o cumprimento dos princípios da justiça internacional, nem a manu- 
tenção das identidades étnicas ainda guardadas em expressões de um nacionalismo legítimo (não ufanista). Daí porque ele não aceita de todo o "modelo de uma sociedade que abrange o mundo" - como defendido por Charles Beitz ${ }^{30}$.

No entanto, é neste modelo (seguido por Beitz) que vejo melhor encarnada a retomada da tradição kantiana, que Koller afinal descreve como um rigorismo moral em que "demandas morais que parecem razoavelmente justificadas, no sentido de serem amplamente aceitáveis [e que] se fossem amplamente acatadas, são obrigatórias, sem exceção, independentemente de outros realmente as aceitarem ou não" ${ }^{31}$.

Admito que há boas razões alegadas pelo comunitarismo para se considerar que alguns países podem legitimamente não aceitar normas acatadas pela maioria dos outros países, mas acredito que, em todos os casos, isso pode ser suplantado por um esquema procedimental deliberativo projetado para a esfera das relações internacionais - um procedimento de tal modo puro que seria inatacável por acusações de substancialismo ${ }^{32}$.

Segundo creio, o que está implícito no kantismo reformulado é o que se deveria ter como o primeiro princípio de uma teoria da justiça internacional: um princípio não-consequencialista de confiança recíproca entre os povos e nações, que de fato desconsidera a funcionalidade de um sistema de proteção internacional, mas - e isso me é bastante - é teoricamente coerente com a tradição deontológica. Esse princípio se somaria a outros, listados por Charles Beitz e mesmo Koller, ligados à justiça social, à paz e aos direitos humanos. Se isso significa uma limitação à soberania dos Estados maior do que aquela cautelosamente pretendida por Koller, suponho que ainda se pode contar, de modo compensatório, para a proteção e garantia dos princípios de justiça internacional, com a cada vez mais concreta e influente sociedade civil global. 


\section{Notas}

${ }^{1}$ Artigo apresentado no XIII Encontro da Associação Nacional de Pós-Graduação em Filosofia, em outubro de 2008, em Canela (RS), com publicação do resumo no Livro de Atas do Encontro.

${ }^{2}$ Bacharel em Direito (UFPA), Licenciado Pleno em Ciências da Religião (UEPA), Mestre em Direitos Fundamentais e Relações Sociais (UFPA), e Doutorando em Relações Internacionais e Desenvolvimento Regional (UNB/FLACSO/ UFRR). Professor Assistente da Universidade Federal de Roraima.

${ }^{3}$ De acordo com Jean-Christophe Merle, "Foi Kant quem inspirou o renascimento das teorias da justiça, desde três décadas [...] Como se sabe, a tese da Paz Perpétua de Kant consiste que em qualquer oportunidade, nenhum Estado republicano poderá querer mais do que uma aliança, tão somente defensiva". Cf. MERLE, Jean-Christophe. Ética kantiana de integração e negociação de ingresso. In: MERLE, Jean-Christophe; MOREIRA, Luiz. Direito e legitimidade. São Paulo: Landy, 2003, p. 344.

${ }^{4}$ Para Celso Lafer, "a seletividade no trato do assunto, no período da Guerra Fria, viu-se bastante impregnada de componentes maquiavélico-hobbesianos típicos de uma política de realismo do poder". Cf. LAFER, Celso. Os direitos humanos no plano internacional: reflexões em torno da 52른 Sessão (1996) da CDH da ONU. In: Baptista, L. O.; Fonseca, J. R. F. da. O direito internacional no terceiro milênio: Estudos em homenagem ao prof. Vicente Marotta Rangel. São Paulo, LTr, 1998, p. 636-637.

${ }^{5} \mathrm{O}$ modus vivendi (modo de viver) a que alude Thomas Hobbes está ligado ao seu modelo de contrato social. Segundo ele, o egoísmo e a dissimulação inatos aos indivíduos (i.e., a ideia do homem como "lobo do próprio homem”) fariam com que qualquer acordo por eles pactuado não afastasse a desconfiança recíproca entre uns e outros. De vez que a qualquer momento o pacto social poderia ser rompido traiçoeiramente por um dos membros, à vista da primeira oportunidade que se lhe beneficiasse, o modo de viver dos indivíduos nesse estado estaria baseado na insegurança permanente no trato com os outros membros da sociedade. A teoria hobbesiana mostrou-se influente em relações internacionais, de modo a projetar esse modus vivendi para as relações diplomáticas entre os países.

${ }^{6}$ A razão estratégica, neste caso, pode ser definida como razão formal voltada à consecução mais eficiente de um fim (racionalidade finalística ou teleológica), como um raciocínio puro que, efetuando cálculos, elabora a estratégia mais adequada para obter o resultado pretendido. Nesse sentido, como tenha transparecido, corresponde a um uso da razão sem preocupações morais; quer dizer, não se trata de razoabilidade. Era exatamente tal modalidade de razão que os Estados, durante a Guerra Fria, empregavam em sua política externa, objetivando formular as estratégias mais adequadas para lidar com os demais países em quem não podiam, ou não queriam, depositar desde logo o voto de confiança.

${ }^{7}$ Para Otfried Höffe: "Na prática política [o Estado soberano] é atropelado pela globalização, além de seu contramovimento, a regionalização”. Cf. HÖFFE, Otfried. Estados nacionais e direitos humanos na era da globalização. In: MERLE, Jean-Christophe; MOREIRA, Luiz. Direito e legitimidade. São Paulo: Landy, 2003, p. 309.

${ }^{8}$ Novamente Lafer: "Essa visão kantiana de uma razão abrangente da humanidade e seus desdobramentos normativos, situados axiologicamente acima da razão dos Estados, inseriram-se, no entanto nas realidades de poder de um sistema internacional de polaridades definidas [...] Apesar das realidades acima descritas, a impregnação kantiana [...] no plano internacional teve suficiente força para atenuar o ímpeto seletivo da política de poder". LAFER, op. cit., p. 637.

${ }^{9}$ HABERMAS, J. A idéia kantiana da paz perpétua - à distância histórica de 200 anos. In: HABERMAS, J. A inclusão do outro. São Paulo: Edições Loyola, 2002.

${ }^{10}$ Kant afirmava, acerca dos fundamentos céticos do pragmatismo da política em relação à moral, no contexto do direito das gentes: “[...] o prático (para quem a moral é pura teoria) funda sua desconsoladora negação de nossa bondosa esperança (mesmo admitindo o dever e o poder) propriamente naquilo que ele pretende prever partindo da natureza do homem, a saber, que este nunca quererá aquilo que é exigido para realizar o fim que conduz à paz perpétua". Cf. KANT, I. Sobre a discordância entre a moral e a política a propósito da paz perpétua. In: KANT, I. Textos seletos. Petrópolis: Vozes, 2005, p. 80.

${ }^{11}$ No presente artigo, entende-se por "procedimentalismo" a corrente teórica que advoga, para a resolução racional de problemas da alçada da filosofia prática, a instituição de um procedimento discursivo-deliberativo. O procedimentalismo retoma a preocupação de Kant com o uso da razão prática, mas reformula o fundamento kantiano baseado em um esquema monológico (o solipsista teste da universalização, por parte de um sujeito racional), propondo então um esquema dialógico, isto é, baseado em um diálogo entre sujeitos (intersubjetivo) racionais, no âmbito de um procedimento que, assentado em regras contraintuitivas, permita-lhes discursar e discutir uns com os outros, de modo a convergirem a um consenso racionalmente aceitável. O procedimentalismo, tal como aqui descrito, encontra em Habermas o seu expoente.

12 Parte significativa do pensamento de Koller sobre a questão aqui tratada foi extraída do seu texto Soberania nacional e justiça internacional (In: MERLE, Jean-Christophe; MOREIRA, Luiz. Direito e legitimidade. São Paulo: Landy, 2003, p. 322-343). 
${ }^{13}$ Para Otfried Höffe, uma etapa na modernização do Estado nacional “consiste em uma tríplice abertura: primeiramente a abertura é feita para criações novas macrorregionais, para comunidades políticas como a União Europeia, que já resolve a maioria dos problemas na sua própria casa. Em segundo lugar, a abertura se dá para uma ordem global do mundo e, em terceiro lugar, para a justiça diante das gerações futuras. Cf. HÖFFE, op. cit., p. 321.

${ }^{14}$ JAKOBS, G.; MELIÁ, Manuel Cancio. Direito penal do inimigo: Noções e críticas. 2ª ed. Porto Alegre: Livraria do Advogado, 2007, passiim.

${ }^{15}$ RAWLS, John. O direito dos povos. São Paulo: Martins Fontes, 2001.

${ }^{16}$ Idem, ibidem, p. XIII.

${ }^{17}$ KOLLER, op. cit. p. 329.

18 "Mundo da vida" (Lebenswelt) é um conceito cunhado pelo filósofo alemão Edmund Husserl e se refere à dimensão da vida onde ocorrem as relações inter-subjetivas processadas através da linguagem. Habermas se apropria desse conceito para com ele designar o mundo das experiências sociais voltadas para a busca de entendimento racional entre as pessoas. Para Habermas, o mundo da vida se depara com uma constante pressão externa advinda dos sistemas de governo e de mercado, os quais, operando a partir de uma lógica baseada no poder e/ou no lucro, obstaculizam o processo de entendimento recíproco e auto-emancipação que deveria caracterizar as interações do mundo da vida. Cf. Mundo da vida e forma de vida: A apropriação habermasiana de Husserl e Wittgenstein, Veritas, no 44/1 (1999): 133-146. Para uma versão completa com as notas e referências bibliográficas, cf. o cap. 8 do Tractatus ethico-politicus (Porto Alegre: Edipucrs, 1999).

${ }^{19}$ KOLLER, op. cit., p. 327.

${ }^{20}$ Segundo ele, “[...] as sociedades do nosso mundo se amalgamaram em um sistema global de mútua cooperação e interdependência, no qual, em diversos aspectos, estão intimamente conectadas umas com as outras, especialmente nos seus assuntos políticos, econômicos, sociais e ecológicos”. Cf. KOLLER, op. cit., p. 328.

${ }^{21}$ Faço minhas as palavras de Ana Paula B. Tostes: "Não pretendo neste artigo enveredar-me no debate sobre a imprecisão conceitual ou equivocidades no uso do conceito de sociedade civil global (disputas conceituais e críticas atuais muito se assemelham ao que se passa há décadas com a definição de globalização e da mesma forma me interessa o processo e não a substância de um conceito perfeito, inconteste ou irrefutável). Partirei, assim, de uma definição abrangente e inclusiva que considere a sociedade civil global como um conjunto de atores que interagem socialmente e são emergentes de lutas por novas formas de identidades transnacionais, ativismos transnacionais e extra-estatais, podendo se organizar em grupos de interesses ou através da constituição de instituições não governamentais transnacionais e internacionais. O resultado que interessa é que esse fenômeno se apresenta com crescente intensidade e vem trazendo consequências para a pesquisa em relações internacionais, logo, suscita pesquisa empírica e reflexão teórica". Cf. TOSTES, Ana Paula B. Identidades transnacionais e o estado. Viço e teimosia? In: Lua Nova, no 63. CEDEC, Centro de Estudos de Cultura Contemporânea, São Paulo, Brasil: Brasil. 2004. Aceso ao texto completo: http://www.scielo. br/pdf/ln/ n63/a03n63.pdf. Complemento que essa "sociedade civil global" seria composta por associações e organizações do chamado Terceiro Setor, cuja atuação, sem fins lucrativos, seria legítima porque assentada na representatividade de grupos sociais vinculados a demandas de projeção internacional.

${ }^{22}$ Nythamar de Oliveira entende que o importante, em $O$ direito dos povos, é a questão da justiça como estabilidade entre sociedades liberais e decentes (a ser alcançada pelo ideal de paz federativa), sem que Rawls se ocupe de "questões de justiça distributiva". Desse modo, a teoria da justiça internacional ora defendida, de forte pretensão igualitária (uma "teoria da justiça social internacional", por assim dizer) não pode ser relacionada à teoria rawlsiana, uma vez que esta "não compartilha de teses cosmopolitas segundo as quais uma teoria da justiça global deve regulamentar as desigualdades entre os povos e impedir que se tornem excessivas". Cf. OLIVEIRA, Nythamar de. Rawls. Rio de Janeiro: Jorge Zahar Editor, 2003, p. 41.

${ }^{23}$ KOLLER, op. cit., p. 326.

${ }^{24}$ Idem, ibidem, p. 329.

${ }^{25}$ Id., ibid.

${ }^{26}$ Id., ibid.

${ }^{27}$ Id., ibid, p. 329.

${ }^{28}$ Id., ibid., p. 329.

${ }^{29}$ Diz o autor: "Desse modo, há uma diferença entre os padrões morais que se aplicam a um mundo ideal, em que todas as partes, ou a maioria delas, por um lado os aceitam, e, por outro, os padrões morais que são obrigatórios sob condições de imperfeição moral. Nesse caso [...] não será suficiente buscar apenas princípios de uma ordem internacional ideal, mas além deles, necessitamos também procurar requisitos que se aplicam às condições moralmente deficientes da realidade". Cf. idem, ibidem, p. 330.

${ }^{30}$ BEITZ, Charles R. Sovereignty and morality in international affairs. In: HELD, D. (ed.). Political theory today. Stanford: Stanford University Press, 1991; idem, Justice and international relations. Philosophy and Public Affairs 4, 
1975, p. 360-389; idem, Political theory and international relations, Princeton: New Jersey, 1979, p. 143 e ss.

${ }^{31}$ KOLLER, op. cit., p. 329.

${ }^{32} \mathrm{Cf}$. nota de rodapé 11 . 


\section{Referências}

BEITZ, C. R. Sovereignty and morality in international affairs. In.: HELD, D. (ed.), Political theory today. Stanford: Stanford University Press, 1991.

HABERMAS, J. A idéia kantiana da paz perpétua - à distância histórica de 200 anos. In.: HABERMAS, J. A inclusão do outro. São Paulo: Edições Loyola, 2002.

HÖFFE, O. Estados nacionais e direitos humanos na era da globalização. In.: MERLE, J.-C.; MOREIRA, L. Direito e legitimidade. São Paulo: Landy, 2003, p. 309-311.

JAKOBS, G.; MELIÁ, M. C. Direito penal do inimigo: Noções e críticas. $2^{a}$ ed. Porto Alegre: Livraria do Advogado, 2007, passim.

KANT, I. À paz perpétua. São Paulo: L\&PM Pocket, 2002.

. Sobre a discordância entre a moral e a política a propósito da paz perpétua. In.: KANT, I. Textos seletos. Petrópolis: Vozes, 2005.

KOLLER, Peter. Soberania nacional e justiça internacional In.: MERLE, J.-C.; MOREIRA, L. Direito e legitimidade. São Paulo: Landy, 2003, p. 322-343.

LAFER, C. Os direitos humanos no plano internacional: reflexões em torno da 52a Sessão (1996) da CDH da ONU. In.: BAPTISTA, L. O.; FONSECA, J. R. F. da. O direito internacional no terceiro milênio: Estudos em homenagem ao prof. Vicente Marotta Rangel. São Paulo, LTr, 1998, p. 635-642.

MERLE, Jean-Chr. Ética kantiana de integração e negociação de ingresso. In.: MERLE, J.-C.; MOREIRA, L. Direito e legitimidade. São Paulo: Landy, 2003, p. 344-354.

OLIVEIRA, N. de. Rawls. Rio de Janeiro: Jorge Zahar Editor, 2003.

RAWLS, J. O direito dos povos. São Paulo: Martins Fontes, 2001.

TOSTES, A. P. B. Identidades transnacionais e o estado. Viço e teimosia? In.: Lua Nova, $n^{\circ} 63$. CEDEC, Centro de Estudos de Cultura Contemporânea, São Paulo, Brasil: Brasil. 2004. Aceso ao texto completo: http://www.scielo. br/pdf/ln/n63/a03n63.pdf. 